\title{
DIFFERENCES IN SOIL PROPERTIES AMONG CONTRASTING SOIL TYPES IN NORTHERN BORNEO
}

\author{
Sellan $\mathbf{G}^{1,2, *}$, Brearley $\mathbf{F Q}^{2}$, Nilus $\mathbf{R}^{3}$, Titin $\mathrm{J}^{3} \&$ Majalap-Lee $\mathbf{N}^{3}$ \\ ${ }^{1}$ CNRS-UMR EcoFoG, Campus Agronomique, 97310, Kourou, French Guiana \\ ${ }_{2}^{2}$ Department of Natural Sciences, Manchester Metropolitan University, Chester Street, Manchester, M1 5GD, UK \\ ${ }^{3}$ Forest Research Centre, Sabah Forestry Department, PO Box 1407, 90715 Sandakan, Sabah, Malaysia \\ *giacomo.sellan@ecofog.gf
}

Submitted May 2020; accepted September 2020

\begin{abstract}
Soil in the tropics is high in diversity, and despite the diversity of Borneo's forest-soil associations, there is a paucity of data on its soil properties. We investigated the differences between three soil types in the Kabili-Sepilok Forest Reserve, Sabah, Malaysia, encompassing the contrasting alluvial, sandstone and heath forest typologies. We examined the distribution of nutrients between soil types and through soil depths, and assessed the extent of spatial autocorrelation in the three soil types. We confirmed the fertility gradient from alluvial to heath forest soil found by others. Soil elemental concentrations declined in deeper horizons with the exception of exchangeable sodium and aluminium that remained constant through alluvial and sandstone soil profiles. Spatial autocorrelation was present in all three soil types and strongest in the sandstone soil. Overall, we show how bedrock, erosion, leaching and topography influence soil properties across this mosaic of soil types and note their importance in influencing tree communities and their ecological functioning.
\end{abstract}

Keywords: Acrisols, Cambisols, clay eluviation, heath forest, nutrient leaching, Podzols, spatial autocorrelation

\section{INTRODUCTION}

Tropical soils are often considered as highly acidic and poor in nutrients but, in reality, pedodiversity in tropical regions is high (Richter \& Babbar 1991). Soil scientists have discussed how sharp soil transitions can occur in the tropics due to contrasting parent materials (Bravard \& Righi 1991, Lundstrom et al. 2000, Fujii et al. 2011) or through weathering and soil transformation (Dubroeucq \& Volkoff 1998). For example, Dubroeucq and Volkoff (1998) considered that clay-rich Ferralsols could transform, over time, to Podzols through kaolinite dissolution. This variation in soil properties is important as soil is the main medium through which plants obtain mineral nutrients and this can therefore influence species performance and, hence, their distributions (Duivenvoorden 1995, Sellan et al. 2019). Several studies showed that even trees of the same genus can specialise to a particular soil type, e.g. Dryobalanops aromatica and Shorea rubra are specialised to sandy soils whereas Dryobalanops lanceolata and Shorea xanthophylla mainly grow on clay soils (Potts et al. 2002).

Among tropical regions, the island of Borneo has a uniform wet climate and hosts one of the most diverse lowland forests in the world (Kier et al. 2005). Although much of the island is covered by typical lowland tropical Acrisols underlain by sedimentary rocks laid down during the Miocene and Pliocene, several abiotic factors lead to high soil variation on the island, with major floristic associations related to soil typologies (e.g. forests over limestone, heath forests, montane forests and ultramafic forests). Many studies across Borneo have analysed soil nutrients at a range of sites but the majority of them only focused on surface layers (to around $10 \mathrm{~cm}$ depth). Given that many nutrient-absorbing fine roots will occur deeper than this, it is also of value to determine elemental changes through soil depth. This will additionally provide insights on leaching processes. Furthermore, the distribution of soil elements is often highly variable across a single soil type (Young \& Hammer 2000). Thus, soil sampling should be performed with the aim of mapping the diversity of the whole soil type. Nonetheless, this could lead to a resourceintensive survey. In order to find a compromise among resources spent on the soil survey and 
soil survey quality, it is of interest to understand the degree to which soil characteristics are spatially autocorrelated within a given soil type.

In order to provide insights into the changes in soil chemistry along a soil fertility gradient, we performed a detailed comparison of soil chemical and physical characteristics through three soil depths at Kabili-Sepilok Forest Reserve (KSFR), in eastern Sabah, Malaysian Borneo. Despite the importance of this study site for ecological research (see for instance Dent et al. 2006, Nilus et al. 2011), in-depth data regarding its soils are, as yet, unpublished. Due to the clear floristic differences between the forest types in this reserve (Nilus 2003), we hypothesise that the soils will have similarly clear differentiation. The aim of this paper was thus, to: (1) describe the differences in chemical composition, texture and element leaching among the three main soil types found in KSFR, (2) describe changes in elemental concentrations through soil depths, and (3) determine the degree of spatial autocorrelation within each soil type.

\section{MATERIALS AND METHODS}

\section{Study site}

KSFR is located at $5^{\circ} 51^{\prime} \mathrm{N}, 117^{\circ} 56^{\prime} \mathrm{E}$ in the state of Sabah, Malaysian Borneo (Figure 1). The climate is perhumid equatorial (Köppen Af) and has a mean annual precipitation of $2975 \mathrm{~mm}$. The soils in the reserve originate from three bedrock types, i.e. mudstone, sandstone and some siltstone whose age is upper Miocene or younger. The reserve hosts three soil associations, mapped locally as Silabukan, Lokan and Maliau (Acres \& Folland 1975). The first (Silabukan) consists of a juxtaposition of Acrisols, Fluvisols and Plinthosols (Figure 2a). These soils are composed of alluvium derived from the erosion of mudstone and sandstone hills. The topography is generally flat with small mudstone hills and hosts the alluvial forest which is very species diverse with an upper canopy height of 45-60 m, trees that can reach a diameter of $2.4 \mathrm{~m}$ or larger and a low understorey density (Nilus 2003). This forest is dominated
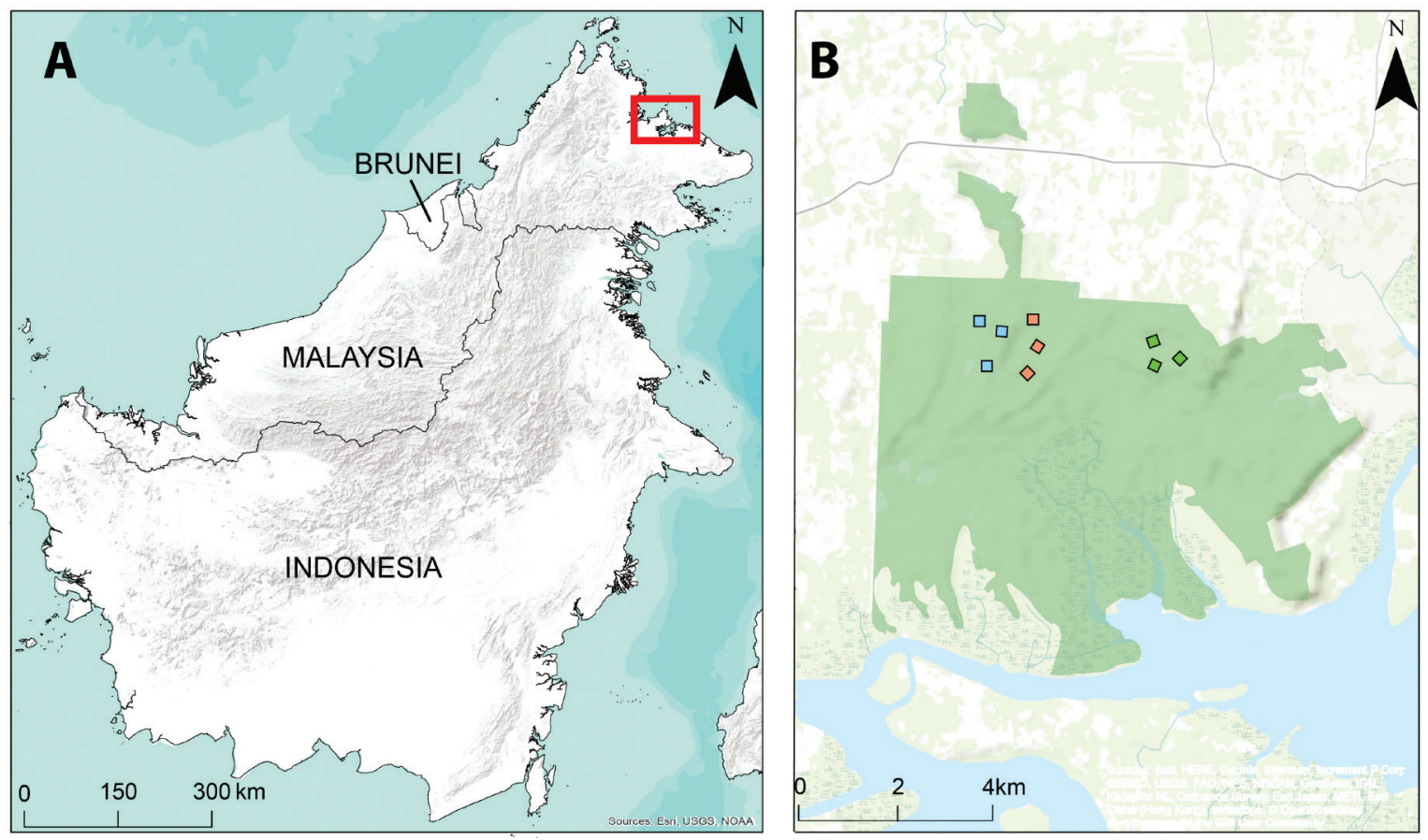

Figure 1 Study sites: (A) the island of Borneo with the approximate position of the Kabili-Sepilok Forest Reserve in Sabah, Malaysia highlighted in red; (B) the nine study plots within the KSFR (dark green); blue squares represent the sandstone plots, red squares represent the alluvial plots and green squares represent the heath forest plots 
by Parashorea tomentella and Eusideroxylon zwageri (Nilus 2003). On the ridges of the hills, the interbedding of sandstone and mudstone leads to the development of Haplic Cambisols and Plinthic Acrisols (Figure 2b) mapped together as the Lokan association. It supports the sandstone forest formation characterised by a lower canopy height (30-40 m), a mean tree diameter intermediate between alluvial and heath forest, and a high understorey density; it is dominated by Dipterocarpus acutangulus and Shorea multiflora (Nilus 2003). The gentle slopes on the side of the hills host the Maliau soil association, which is composed of Haplic Acrisols (Figure 2c) with some podzolised areas characterised by the presence of bleached sand, often with an indurated hardpan. This soil formation gives rise to the heath forest or kerangas, which is dominated by Shorea multiflora and Tristaniopsis merguensis, has a very high understorey stem density, an even canopy of 25-30 m in height with small tree crowns and low species diversity (Nilus 2003, Sellan et al. 2019).

\section{Soil sampling}

In each of the three forest-soil associations, three 4-ha forest plots were installed for a total of nine square plots. Every plot was divided into $20 \mathrm{~m} \times 20 \mathrm{~m}$ blocks and we undertook a soil survey that sampled one fifth of the randomly selected blocks in each plot. In total, 20 blocks from each plot were sampled, totalling 180 blocks. The precise geographic location of the sampled blocks were obtained from Jucker et al. (2018). In each block, we collected five soil samples of approximately $5 \mathrm{~cm} \times 5 \mathrm{~cm} \times 5 \mathrm{~cm}$ at three depths $(0-5 \mathrm{~cm}, 5-20 \mathrm{~cm}$, and $20-35 \mathrm{~cm}$, which roughly covered soil $\mathrm{A}$ and upper and lower B horizons) and subsequently bulked the five samples from each depth together and ground them to pass a $2-\mathrm{mm}$ sieve. The five soil samples were collected near the four corners of the block and one from the centre. In total, 540 samples were analysed. In addition, we excavated one soil pit per forest-soil association to determine the major soil type in the plots. From these soil pits, we sampled each soil horizon for chemical analysis.

\section{Chemical analysis}

Subsamples were taken in duplicate from each fresh sample and extracted for mineral-N with $1.5 \mathrm{~N} \mathrm{KCl}$ at a ratio of 1:15 w:v (adapted from Rowell 1994) then analysed for ammonium $\left(\mathrm{NH}_{4}{ }^{+}\right)$and nitrate $\left(\mathrm{NO}_{3}^{-}\right)$using a flow injection analyser and the indophenol blue and sulphanilamide red methods for $\mathrm{NH}_{4}{ }^{+}$and $\mathrm{NO}_{3}{ }^{-}$respectively. The remaining samples were air dried to constant mass, then ground and sieved through a 2-mm sieve and homogenised thoroughly before analysis. Moisture content was determined gravimetrically by drying the soil at $105^{\circ} \mathrm{C}$ until subsamples reached constant weights and used to convert the results to ovendry mass. For total $\mathrm{C}$ and $\mathrm{N}$, the subsamples were ground further to pass through a 100-mesh sieve $(212 \mu \mathrm{m})$ and then quantified by dry combustion with a CN analyser. Soil texture was analysed following Day (1965) through soil digestion with $\mathrm{H}_{2} \mathrm{O}_{2}$, fine earth dispersion with $\mathrm{NaOH}$, and separation of sand, clay and silt with a pipette apparatus. Soil $\mathrm{pH}$ was measured with
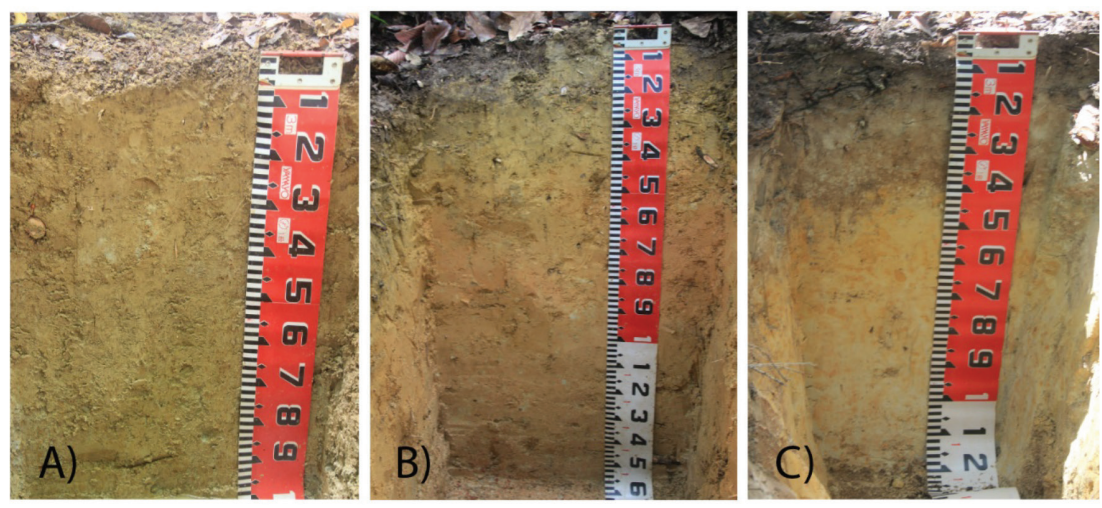

Figure 2 Soil pits excavated in the three main forest/soil types in the Kabili-Sepilok Forest Reserve, Sabah, Malaysia; (A) alluvial forest soil (Haplic Fluvisol), (B) sandstone forest soil (Haplic Cambisol), and (C) heath forest soil (Haplic Acrisol) 
a $\mathrm{pH}$ meter and a combination glass-calomel electrode in a 1:2.5 suspension in water. We determined soil organic $\mathrm{C}$ (only in samples from the soil pits) using the Walkley-Black method (Anderson \& Ingram 1993). Extraction of soil available $\mathrm{P}$ followed the Bray 2 method from Bray and Kurtz (1945) and colorimetric determination described in Anderson and Ingram (1993). Ammonium acetate (1 M; 1:10 w:v) extracts (Thomas 1982, Gillman et al. 1983) were measured for exchangeable $\mathrm{Ca}, \mathrm{Mg}, \mathrm{Na}$ and $\mathrm{K}$ using atomic absorption spectrophotometry while extracts in $1 \mathrm{M} \mathrm{KCl} \mathrm{(1:15} \mathrm{w:v)} \mathrm{were} \mathrm{titrated}$ with $0.1 \mathrm{~N} \mathrm{NaOH}$ and then back-titrated with $0.1 \mathrm{~N} \mathrm{HCl}$ to determine exchangeable acidity and Al (Anderson \& Ingram 1993). Cation exchange capacity was calculated as the sum of exchangeable base cations and exchangeable acidity (i.e. effective cation exchange capacity or ECEC) and base saturation was calculated as the percentage of ECEC occupied by the exchangeable bases.

\section{Statistical analysis}

All the analysis were conducted using R 3.5.1 (R Development Core Team 2018). We assessed whether soil type, soil depth or an interaction of the two had greater influence on element concentrations and texture variation by comparing the F-statistic of a linear mixed effect model (lme function from the nlme R package; Pinheiro et al. 2018) which had the interaction of soil type with depth as a fixed effect and plot as a random effect. ANOVA was used to test the differences in elements between soil types and a Tukey HSD test was performed for variables with $\mathrm{p} \leq 0.05$. To graphically highlight the differences in soil chemistry and texture among the three soil types, a principal components analysis (PCA) was performed on the scaled and centred soil variables. To understand the extent of spatial autocorrelation within the three soil types we firstly inspected whether soil fertility (considered as the scores of $0-5 \mathrm{~cm}$ depth samples on the PCA first axis) showed global spatial autocorrelation using the Moran's I statistic on the PCA first axis values separately for each soil type. Secondly, we assessed at which distance soil fertility (considered as the scores of $0-5 \mathrm{~cm}$ depth samples on the PCA first axis) was spatially autocorrelated by plotting a spatial cross-correlogram using the spline.correlog function from the ncf $R$ package (Bjørnstad
\& Cai 2019). This function estimates spatial dependence as a continuous function of distance (rather than binning the data into distance classes) and calculates $95 \%$ confidence intervals by bootstrapping (1000 times) the original data. Soil fertility was considered as coordinates of the samples on the first axis of a PCA built with only ECEC, base saturation, available phosphorus, $\mathrm{NH}_{4}^{+}, \mathrm{NO}_{3}^{-}$and total $\mathrm{N}$ (Figure 1A in Appendix). We plotted the value of the $0-5 \mathrm{~cm}$ depth samples on this PCA first axis on a map.

\section{RESULTS}

Representative soil pits from the three soil-forest associations are shown in Figure 2. The linear mixed effect model showed that, between plots, soil chemistry variability was best explained by soil depth, whereas soil texture was most related to soil type. The interaction of soil depth with soil type was the most significant for changes in $\mathrm{NO}_{3}{ }^{-}$and exchangeable acidity (Table 1 ). Generally, elemental concentrations declined from the $0-5 \mathrm{~cm}$ horizon to the $5-20 \mathrm{~cm}$ horizon by around $50 \%$, with a further decrease of around $30 \%$ to the $20-35 \mathrm{~cm}$ horizon, except for $\mathrm{Al}$, which increased, and $\mathrm{Na}$, which was relatively stable, except in the heath forest soil where it declined sharply (Table 2). Soil $\mathrm{NO}_{3}^{-}$was around 10 times greater in the alluvial soil, where it also had the sharpest decrease through depth, whereas exchangeable acidity decreased with depth in the heath forest soil, increased with depth in the alluvial soil and did not change through the sandstone soil profile. Soil $\mathrm{C}$ and $\mathrm{N}$ showed the greatest decreases through soil depth overall, followed by available P (especially in the alluvial soil).

All chemical and physical characteristics analysed with the soil $\times$ depth model showed clear variation between the three soil types. Surprisingly, soil pH was the most similar property between soil types (Table 2). Available $\mathrm{P}$ had the greatest variation ranging from 0.38 to $51.29 \mu \mathrm{g} \mathrm{g}^{-1}$ in the alluvial and heath forest soil samples respectively. Heath forest soil had the lowest $\mathrm{NH}_{4}{ }^{+}$concentrations and exchangeable acidity, exchangeable Al, Na and ECEC (Table 2). Heath forest soil had an intermediate base saturation between the alluvial and sandstone soil (Table 2). The difference between alluvial and sandstone soil was clear for all elements except total C, which was similar between these 
Table 1 F statistics for the three fixed effects of the linear mixed models between soil variables and a soil type $\times$ sampling depth interaction (which all had $\mathrm{p}<0.001$ in all the models) for three soil associations in the KabiliSepilok Forest Reserve, Sabah, Malaysia

\begin{tabular}{|c|c|c|c|c|}
\hline \multirow{2}{*}{\multicolumn{2}{|c|}{ Soil variable }} & \multicolumn{3}{|c|}{ Soil $\times$ Depth } \\
\hline & & \multirow{2}{*}{$\begin{array}{r}\text { Soil } \\
0.1\end{array}$} & \multirow{2}{*}{$\begin{array}{r}\text { Depth } \\
282.8\end{array}$} & \multirow{2}{*}{$\begin{array}{c}\text { Soil:Depth } \\
128.3\end{array}$} \\
\hline $\mathrm{pH}$ & & & & \\
\hline Moisture conte & & 38.8 & 53.6 & 33.5 \\
\hline Total C & & 4.8 & 681.6 & 3.9 \\
\hline Total N & & 11.4 & 531.6 & 18.1 \\
\hline $\mathrm{NO}_{3}^{-}$ & & 12.9 & 127.7 & 194.9 \\
\hline $\mathrm{NH}_{4}^{+}$ & & 1.3 & 104.4 & $<0.1$ \\
\hline Available P & & 1.5 & 348.7 & 1.1 \\
\hline \multirow{6}{*}{ Exchangeable } & Acidity & 56.7 & 2.5 & 110.2 \\
\hline & $\mathrm{Al}$ & 78.3 & 18.9 & 71.9 \\
\hline & $\mathrm{Ca}$ & 7.8 & 34.1 & 30.3 \\
\hline & $\mathrm{Mg}$ & 10.1 & 34.4 & 2.6 \\
\hline & $\mathrm{K}$ & 8.8 & 184.4 & 1.2 \\
\hline & $\mathrm{Na}$ & 35.9 & 103.5 & 72.6 \\
\hline \multicolumn{2}{|l|}{ ECEC } & 35.4 & 199.0 & 42.8 \\
\hline \multicolumn{2}{|l|}{ Base saturation } & 1.0 & 161.9 & 1.6 \\
\hline \multicolumn{2}{|l|}{ Clay } & 51.3 & 14.6 & 0.3 \\
\hline \multicolumn{2}{|l|}{ Silt } & 26.4 & 2.7 & 0.1 \\
\hline \multicolumn{2}{|l|}{ Sand } & 38.8 & 11.8 & 0.1 \\
\hline
\end{tabular}

ECEC = effective cation exchange capacity

two soil types (Table 2). Total C increased and total $\mathrm{N}$ decreased from the alluvial to the heath forest soil (Table 2). Soil texture was significantly different across the three soil types. The sand fraction had the greatest variation between soils and was predominant (c. $75 \%$ ) in the heath forest soil.

The PCA first axis (Figure 3) explained $47 \%$ of the variance and showed a gradient from soils with high sand content to soils with high ECEC and moisture content. The second PCA axis explained $19 \%$ of the variance and was characterised by a gradient from soils with high exchangeable $\mathrm{Al}$ and acidity (alluvial and sandstone) to soils with high $\mathrm{C}$ and available $\mathrm{P}$ concentrations (heath forest).

The Moran's I calculated with the scores of samples at $0-5 \mathrm{~cm}$ depth on the PCA first axis was more negative for the sandstone $(I=-0.13$, $\mathrm{p}<0.001)$ soil than for alluvial $(\mathrm{I}=-0.08, \mathrm{p}<$ $0.001)$ and heath forest soils $(\mathrm{I}=-0.08, \mathrm{p}<0.001)$, indicating greater spatial autocorrelation for the sandstone soil (Figure 4).
The Moran's I cross-correlograms (Figure 5) showed that the sandstone and heath forest soils had significant positive spatial correlations within the first $100 \mathrm{~m}$.

\section{DISCUSSION}

With this work, we present the most detailed soil survey undertaken in the KSFR throughout three different soil-forest associations. We confirmed the fertility gradient already formulated by others for this area (alluvial $>$ sandstone $>$ heath forests; Nilus 2003, Dent et al. 2006) and also shown for other similar study sites on the island of Borneo (Proctor et al. 1983, Vernimmen et al. 2013, Metali et al. 2015). Spatial autocorrelation is greater in the sandstone soil and is most significant within the first $100 \mathrm{~m}$ in sandstone and heath forest soil types.

Ammonium is the dominant form of mineral nitrogen in sandstone and heath forest soil whereas $\mathrm{NO}_{3}^{-}$is the dominant form in alluvial soil. This difference might be due to the effect 


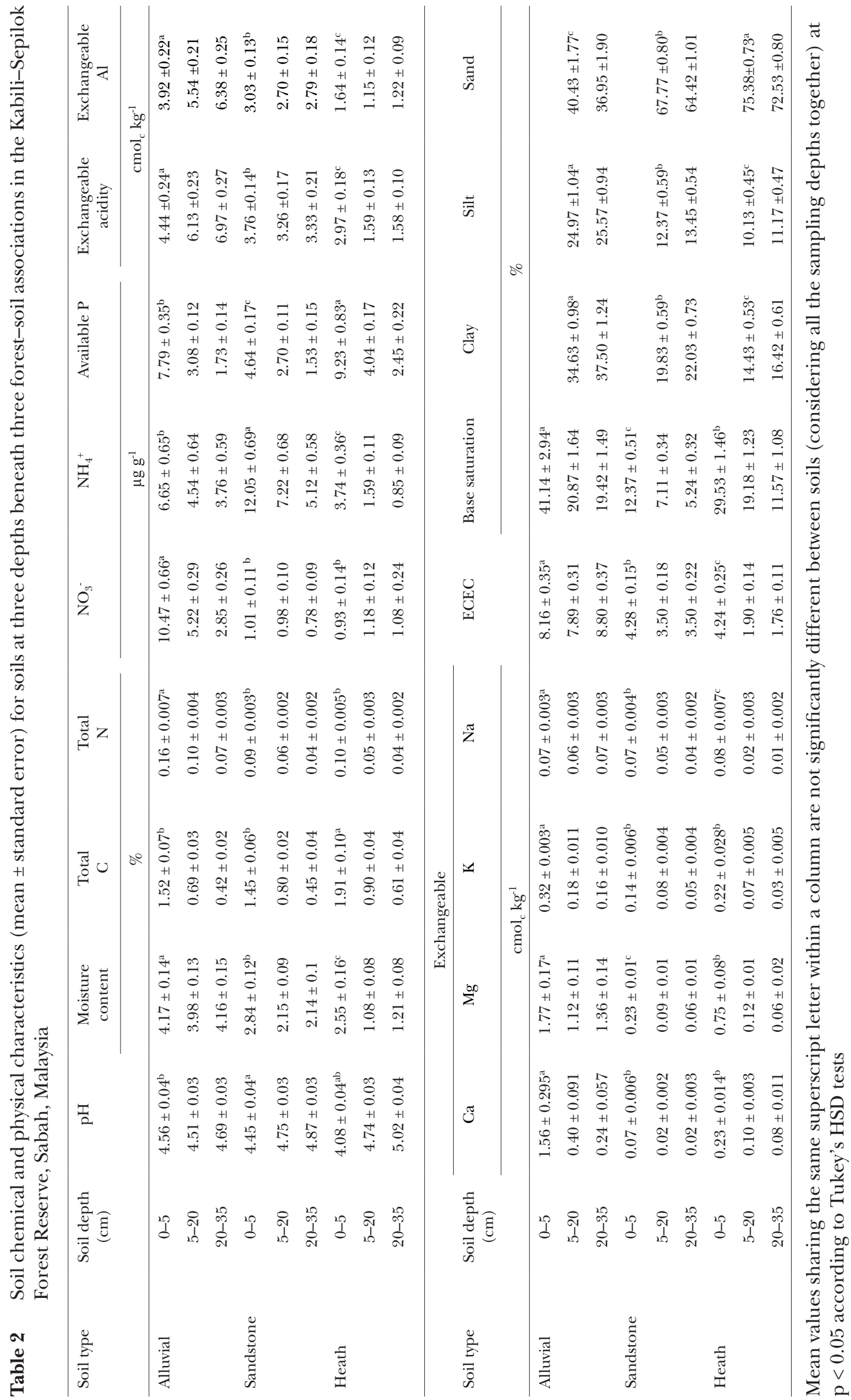


of leaf litter quality, soil moisture and soil acidity. Alluvial forest litter usually has the lowest C:N ratio (Dent et al. 2006) and the least acidic soil $\mathrm{pH}$, which together favour nitrification (Zaman \& Chang 2004). The greater concentration of $\mathrm{NH}_{4}{ }^{+}$in sandstone than in the heath forest soil might be due to a greater ability for $\mathrm{NH}_{4}{ }^{+}$uptake by heath forest trees, given that these trees live in an acidic and $\mathrm{N}$-poor environment.

Effective CEC, as expected, decreased from alluvial to heath forest soil, whereas base saturation was greater in the heath forest soil than in the sandstone soil. This could lead to the conclusion that the former was more fertile, but this was not the case. The difference in base saturation between the two soils in fact was driven by the low extractable $\mathrm{Al}$ and exchangeable acidity of the heath forest soil, which increased the relative base saturation. Our analysis revealed the most acidic soils (heath forest) have the least extractable $\mathrm{Al}$ despite the classical paradigm of a positive correlation of $\mathrm{Al}$ with soil acidity (e.g. Quesada et al. 2012). In this regard, several researchers reported Podzols to be poorer in
$\mathrm{Al}$ when compared with Acrisols and Ferralsols (Andriesse 1975, Vernimmen et al. 2013) as Al in tropical soils derives mainly from the weathering of clay minerals, but, in Podzols, $\mathrm{Al}$ is eluviated through the soil profile along with $\mathrm{Fe}$ (Lundstrom et al. 2000). Proctor (1999) and Kidd and Proctor (2001) proposed the lack of $\mathrm{Al}$ in Podzols to be the reason for their unique acidity, as in other tropical soils, $\mathrm{Al}$ buffers the effect of $\mathrm{H}^{+}$ions on $\mathrm{pH}$. Extractable $\mathrm{Al}$ is also negatively correlated with available $\mathrm{P}$ throughout the three soils (as seen from the second PCA axis in Figure 3). Heath forest soils, for example, have the greatest available $\mathrm{P}$ concentration and this is likely due to their low $\mathrm{Al}$ concentration, which (along with $\mathrm{Fe}$ ) binds $\mathrm{P}$ in the alluvial and sandstone soils. Although we did not measure soil Fe, data from Sellan et al. (2019) suggests that our heath forest has low soil Fe concentration. On the other hand, the high available $\mathrm{P}$ concentration (up to c. $50 \mu \mathrm{g} \mathrm{g}^{-1}$ ) in heath forest soil might be, at least partly, an artefact of the weak acid extraction method used and not directly represent what is available to plants.

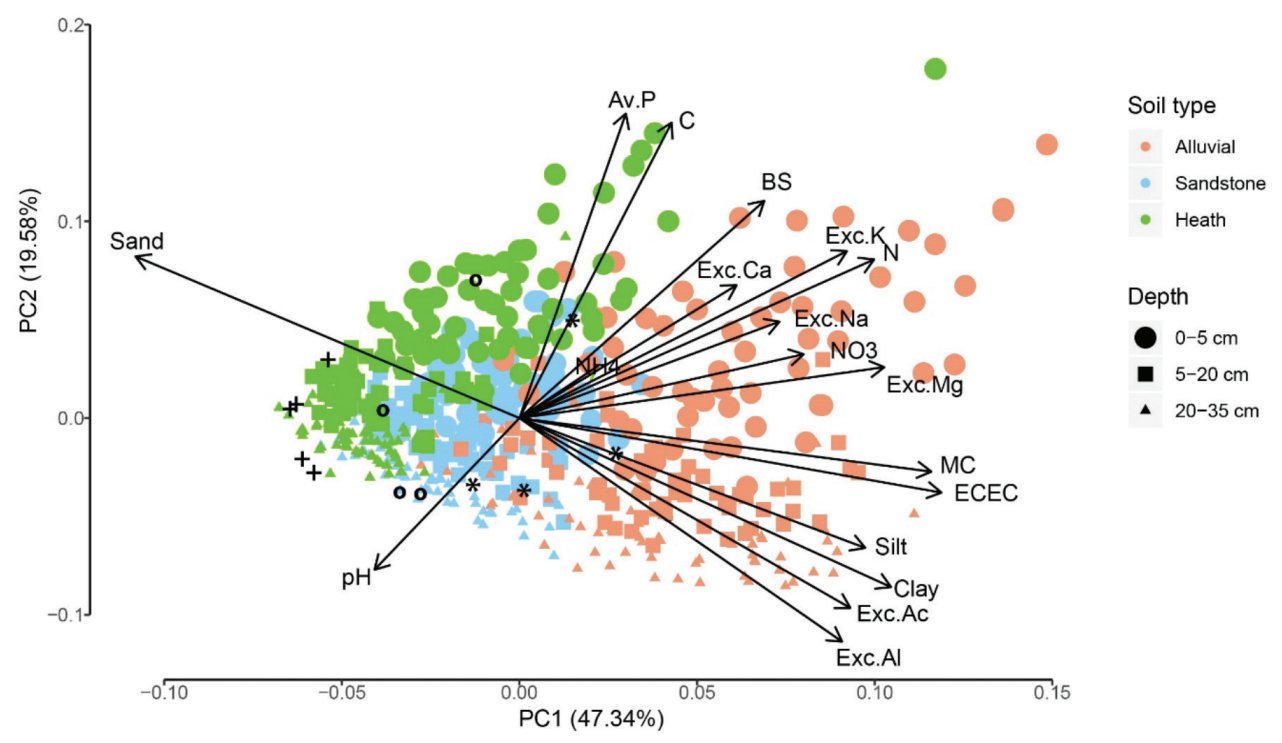

Figure 3 Principal component analysis of soil variables in three soil types in the Kabili-Sepilok Forest Reserve, Sabah, Malaysia; abbreviations are as follows: total $\mathrm{N}(\mathrm{N})$, total $\mathrm{C}(\mathrm{C})$, available $\mathrm{P}$ (Av.P), exchangeable $\mathrm{Al}$ (Exc.Al), exchangeable acidity (Exc.Ac), exchangeable Mg (Exc.Mg), exchangeable $\mathrm{Na}$ (Exc.Na), exchangeable Ca (Exc.Ca), exchangeable K (Exc.K), ammonium (NH4), nitrate (NO3), effective cation exchange capacity (ECEC), base saturation (BS) and moisture content (MC); also plotted are the samples taken from the three soil pits at four (alluvial and sandstone) and five (heath forest) depths; symbols are "+" for heath forest, "o" for sandstone and “*” for alluvial samples 


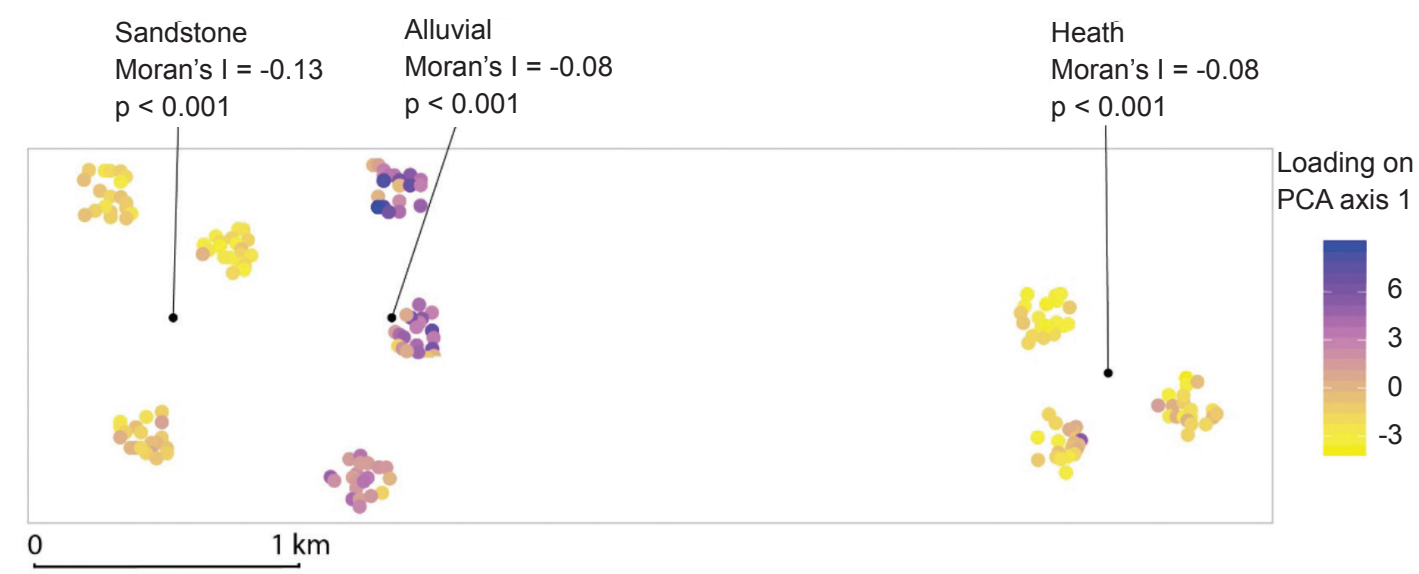

Figure 4 Location of soil sampling points in the Kabili-Sepilok Forest Reserve, Sabah, Malaysia and spatial autocorrelation of soil properties within each forest-soil association; the colour of the sampling points represents the loading of the $0-5 \mathrm{~cm}$ depth samples on the first axis of a PCA built with the fertility variables as in Figure 1A
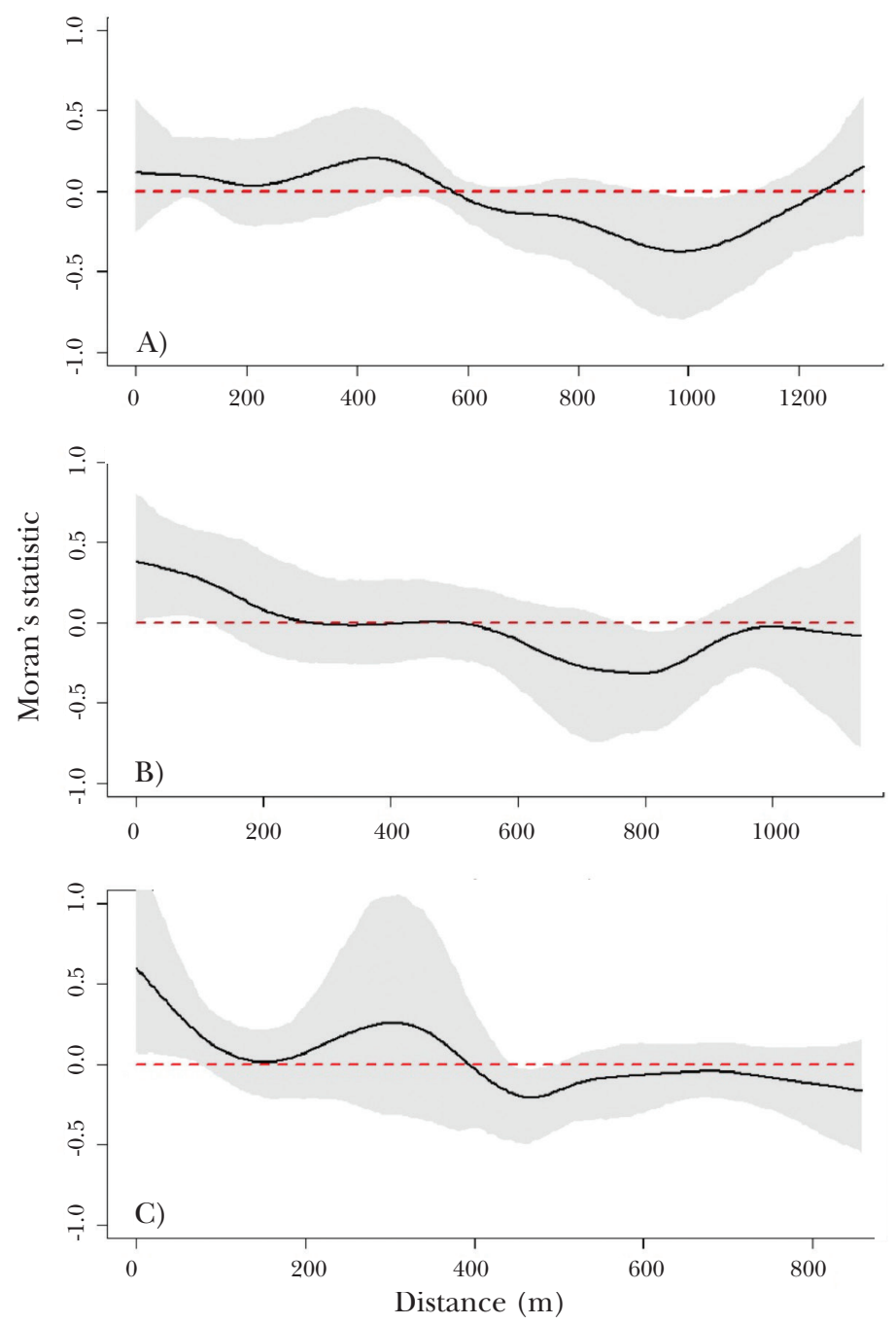

Figure 5 Spatial correlograms of the 0-5 cm soil sample loadings on the PCA first axis with Moran's I averaged per distance classes; the correlograms were conducted separately for alluvial (A), sandstone (B) and heath forest (C) soil samples collected in the Kabili-Sepilok Forest Reserve, Sabah, Malaysia; red line indicates no spatial autocorrelation (Moran's $I=0$ ) whereas grey shading indicates the $95 \%$ confidence intervals calculated by bootstrapping the original data 
Aluminium accumulated through the alluvial soil profile, whereas it remained constant with depth in the sandstone soil profile. The concentration was least and it declined only slightly through the heath forest soil profile. This would imply that our heath forest soil was still undergoing podzolisation. Magnesium seemed to accumulate in deeper layers of the alluvial soil, whereas in the heath forest soil it was concentrated in the upper horizon suggesting a tighter cycle and, thus, maybe a limitation. Moran et al. (2000) showed a Brunei heath forest soil to be high in $\mathrm{Ca}$ in contrast to our heath forest soil, and it could be seen how Ca was concentrated at the surface of all the three forest types, suggesting that these soils (in particular the sandstone forest) had inadequate amount of Ca for plant growth. This also appears to be the case for Peninsular Malaysian heath forest soil (in Terengganu) that has a Ca concentration (Khairil \& Burslem 2018) similar to the Ca concentration we found. With regard to other elements, in the heath forest soil, $\mathrm{Mg}, \mathrm{K}$ and $\mathrm{Na}$ were more concentrated in the topsoil and presented a clear decline with depth likely due to stronger leaching in sandy heath forest soil. Greater element concentrations in topsoil are likely driven by the rapid cycling among litterfall and root/mycorrhizal components (Jobbagy \& Jackson 2001).

The negative Moran's I of the PCA first axis revealed that the sandstone soil samples were the most spatially autocorrelated, being more dispersed overall than expected randomly, consistent with the Moran's cross-correlograms. This clear spatial autocorrelation might be due to the sandstone forest's topography, which comprises the steepest slopes in the KSFR (Jucker et al. 2018). Samples collected at the same geographical exposition (e.g. northexposed) on a ridge of the same plot could thus be more similar than samples collected at different expositions, and this would lead to a high positive local spatial autocorrelation, and to a high negative overall spatial autocorrelation. The alluvial plots, by contrast, are located on much flatter topography, which might produce a more homogeneous environment with a resulting lower spatial autocorrelation, i.e. more random distribution. All the three soil types showed negative spatial autocorrelation (albeit not significant) at greater distances $(\sim 400$ to
$600 \mathrm{~m}$ and further). Nonetheless, here we interpreted the cross-correlograms only in the first section (until the average Moran's I line crossed the zero value) because the inference of spatial autocorrelation over larger distances are less reliable (Bjørnstad \& Falck 2001). The cross-correlograms also suggested that, in order to represent the maximum variability within each soil type without incurring spatial autocorrelation, samples should be collected at a distance of $\sim 100 \mathrm{~m}$ among each other in sandstone and heath forest soil.

The three soils had developed from the interaction of different parent materials underlying the plots (Acres \& Folland 1975), different topography and different erosional characteristics. The high variance of soil texture in alluvial soil might be due to the small mudstone hills present in the alluvium, which locally increased the amount of clay. Furthermore, the flat topography of alluvial forests was likely to reduce the effects of weathering and erosion. Both sandstone and heath forest soils are derived from a mixture of sandstone and mudstone bedrock, and differ among themselves possibly because of more mudstone-derived clay in sandstone soil. In this way, it was easy to understand that the low variability of heath forest soil texture was due to the prominent role of sandstone bedrock in soil formation.

Differential erosion due to topography was also likely to play a role in shaping these soils. Andriesse (1968) showed that Podzols usually develop on slopes less than $15 \%$. Sandstone forest has a general slope $>20 \%$ and heath forest has 10-20\% slopes. Furthermore, Andriesse (1970) suggests that the podzolisation process requires around 5000 years to be accomplished in the tropics. Heath forests generally show a characteristic podzolised soil profile with a greywhite sandy A-B horizon with weathered clay, eluviated $\mathrm{Fe}$ and $\mathrm{Al}$ underlain by an indurated hardpan (Andriesse 1968, Dubroeucq \& Volkoff 1998). However, our soil pits showed heath forest soil to be Haplic Acrisols without a hardpan, although we did find Podzols elsewhere-notably where forest biomass was lower (Sellan et al. 2019). Given the fact that Acrisols can develop into Podzols (do Nascimento et al. 2004), and that $\mathrm{Al}$ seem to be quite constant through heath forest soil profile, we suspect that our heath forest soil may be in a stage of incipient podzolisation. 


\section{CONCLUSIONS}

We compared the chemo-textural properties of three adjacent forest-soil associations in Malaysian Borneo. We expected the sandstone and heath forest soils to be more similar given their bedrock geological similarity but the differences are probably due to the incipient podzolisation process ongoing in heath forest soils. High Al concentration correlated with low $\mathrm{P}$ availability in the least acidic and more clayrich soils, whereas in the Al-poor heath forest soil, available $\mathrm{P}$ was more abundant. Spatial autocorrelation was greater in the sandstone, and secondarily heath forest, soil possibly due to their more variable topography. To overcome spatial autocorrelation we suggest that further soil surveys in areas adjacent or similar in topography to our study site should consider a minimum distance of $\sim 100 \mathrm{~m}$ among samples collected in hilly landscapes.

\section{ACKNOWLEDGEMENTS}

The authors are grateful to the research assistants from the Soil Chemistry, Soil Science and Ecology sections from the Kabili-Sepilok Forest Research Centre, Guillermo Bueno for the statistical advice and Tommaso Jucker for providing the geographic location of the sampled blocks.

\section{REFERENCES}

ACres BD \& Folland CJ. 1975. The Soil of Sabah. Volume 2: Sandakan and Kinabatangan Districts. Ministry of Overseas Development, Surbiton.

Anderson JM \& Ingram JSI. 1993. Tropical Soil Biology and Fertility: A Handbook of Methods. Second Edition. CAB International, Wallingford.

Andriesse JP. 1968. A study of the environment and characteristics of tropical podzols in Sarawak (eastMalaysia). Geoderma 2: 201-227.

Andriesse JP. 1970. The development of the podzol morphology in the tropical lowlands of Sarawak (Malaysia). Geoderma 3: 261-279.

Andriesse JP. 1975. Characteristics and formation of so-called Red-Yellow Podzolic soils in the humid tropics (Sarawak-Malaysia). PhD thesis, University of Utrecht, Utrecht.

BJørnstad ON \& Falck W. 2001. Nonparametric spatial covariance functions: estimation and testing. Environmental and Ecological Statistics 8: 53-70.

BJøRnstad ON \& CaI J. 2019. ncf. Spatial Covariance Functions. $\mathrm{R}$ package version 1.2-8.

Bravard S \& Righi D. 1991. Characterization of fulvic and humic acids from an oxisol-spodosol toposequence of Amazonia, Brazil. Geoderma 48: 151-162.
BRAY RH \& KURTZ LT. 1945. Determination of total, organic and available forms of phosphorus in soils. Soil Science 59: 39-45.

DAY PR. 1965. Particle fractionation and particle-size analysis. Pp 545-567 in Black CA (ed) Methods of Soil Analysis Part 1. Physical and Mineralogical Properties, Including Statistics of Measurement and Sampling. American Society of Agronomy, Madison.

Dent DH, Bagchi R, Robinson D, Majalap-Lee N. \& Burslem DFRP. 2006. Nutrient fluxes via litterfall and leaf litter decomposition vary across a gradient of soil nutrient supply in a lowland tropical rain forest. Plant and Soil 288: 197-215.

Dubroeuce D \& Volkoff B. 1998. From oxisols to spodosols and histosols: evolution of the soil mantles in the Rio Negro basin (Amazonia). Catena 32: 245-280.

Duivenvoorden JE. 1995. Tree species composition and rain forest-environment relationships in the middle Caqueta area, Colombia, NW Amazonia. Vegetatio 120: 91-113.

Fuji K, Hartono A, Funakana S, Uemura M, Sukartiningsim \& Kosaki T. 2011. Distribution of Ultisols and Oxisols in the serpentine areas of East Kalimantan, Indonesia. Pedologist 55: 63-76.

Gillman GP, Bruce RC, Davey BC, Kimble IM, Searle, PL \& SKJEMSTAD JO. 1983. A comparison of methods used for determination of cation exchange capacity. Communications in Soil Science and Plant Analysis 14: 1005-1014.

Jobbagy EG \& Jackson RB. 2001. The distribution of soil nutrients with depth: global patterns of the imprint of plants. Biogeochemistry 53: 51-77.

Jucker T, Bongalov B, Burslem DFRP et al. 2018. Topography shapes the structure, composition and function of tropical forest landscapes. Ecology Letters 21: 989-1000.

Khairil M \& Burslem DFRP. 2018. Controls on foliar aluminium accumulation among populations of the tropical shrub Melastoma malabathricum L. (Melastomataceae). Tree Physiology 38: 1752-1760.

KidD PS \& Proctor J. 2001. Why plants grow poorly on very acid soils: are ecologists missing the obvious? Journal of Experimental Botany 52: 791-799.

Kier G, Mutke J, Dinerstein E, Ricketts TH, KüPer W, Kreft H \& Barthlott W. 2005. Global patterns of plant diversity and floristic knowledge. Journal of Biogeography 32: 1107-1116.

Lundstrom US, Van Breemen N \& Bain D. 2000. The podzolization process. A review. Geoderma 94: 91-107.

Metali F, Abu Salim K, Tennakoon K \& Burslem DFRP. 2015. Controls on foliar nutrient and aluminium concentrations in a tropical tree flora: phylogeny, soil chemistry and interactions among elements. New Phytologist 205: 280-292.

Moran JA, Barker MG, Moran AJ, Becker P \& Ross SM. 2000. A comparison of the soil water, nutrient status, and litterfall characteristics of tropical heath and mixeddipterocarp forest sites in Brunei. Biotropica 32: 2-13.

do Nascimento NR, Bueno GT, Fritsch E et al. 2004. Podzolization as a deferralitization process: a study of an Acrisol-Podzol sequence derived from Palaeozoic sandstones in the northern upper Amazon Basin. European Journal of Soil Science 55: 523-538. 
Nilus, R. 2003. Effect of edaphic variation on forest structure, dynamics and regeneration in a lowland tropical rainforest in Borneo. PhD thesis, University of Aberdeen, Aberdeen.

Nilus R, Maycock CR, Majalap-Lee N \& Burslem DFRP. 2011. Nutrient limitation of tree seedling growth in three soil types found in Sabah. Journal of Tropical Forest Science 23: 133-142.

Pinheiro JC, Bates DM, Debroy S \& Sarkar D. 2018. nlme: Linear and Nonlinear Mixed Effects Models. R package version 3.1-137.

Potts MD, Ashton PS, Kaufman LK \& Plotkin JB. 2002. Habitat patterns in tropical rain forests: a comparison of 105 plots in Northwest Borneo. Ecology 83: 2782-2797.

Proctor J. 1999. Heath forests and acid soils. Botanical Journal of Scotland 51: 1-14.

Proctor J, Anderson JM, Chai P \& Vallack HW. 1983. Ecological studies in four contrasting lowland rain forests in Gunung Mulu National Park, Sarawak: I. Forest environment, structure and floristics. Journal of Ecology 71: 237-260.

Quesada CA, Phillips OL, Schwarz M et al. 2012. Basin-wide variations in Amazon forest structure and function are mediated by both soils and climate. Biogeosciences 9: 2203-2246.
Richter DD \& BABBAR LI. 1991. Soil diversity in the tropics. Advances in Ecological Research 21: 315-389.

Rowell DL. 1994. Soil Science, Methods and Applications. Longman Group UK Limited, Harlow.

Sellan G, Thompson J, Majalap N \& Brearley FQ. 2019. Soil characteristics influence species composition and forest structure differentially among tree size classes in a Bornean heath forest. Plant and Soil 438: 173-185.

Thomas GW. 1982. Exchangeable cations. Pp 159-165 in Page AL ET AL. (eds) Methods of Soil Analysis. Part 2. Second edition. American Society of Agronomy, Madison.

Vernimmen RRE, Brujjnzeel LA, Proctor J, Verhoef HA \& KLomp NS. 2013. Does water stress, nutrient limitation, or H-toxicity explain the differential stature among heath forest types in Central Kalimantan, Indonesia? Biogeochemistry 113: 385-408.

Young F \& Hammer R. 2000. Defining geographic soil bodies by landscape position, soil taxonomy, and cluster analysis. Soil Science Society of America Journal 64: 989-998.

Zaman M \& Chang SX. 2004. Substrate type, temperature, and moisture content affect gross and net $\mathrm{N}$ mineralization and nitrification rates in agroforestry systems. Biology and Fertility of Soils 39: 269-279. 


\section{Appendix}

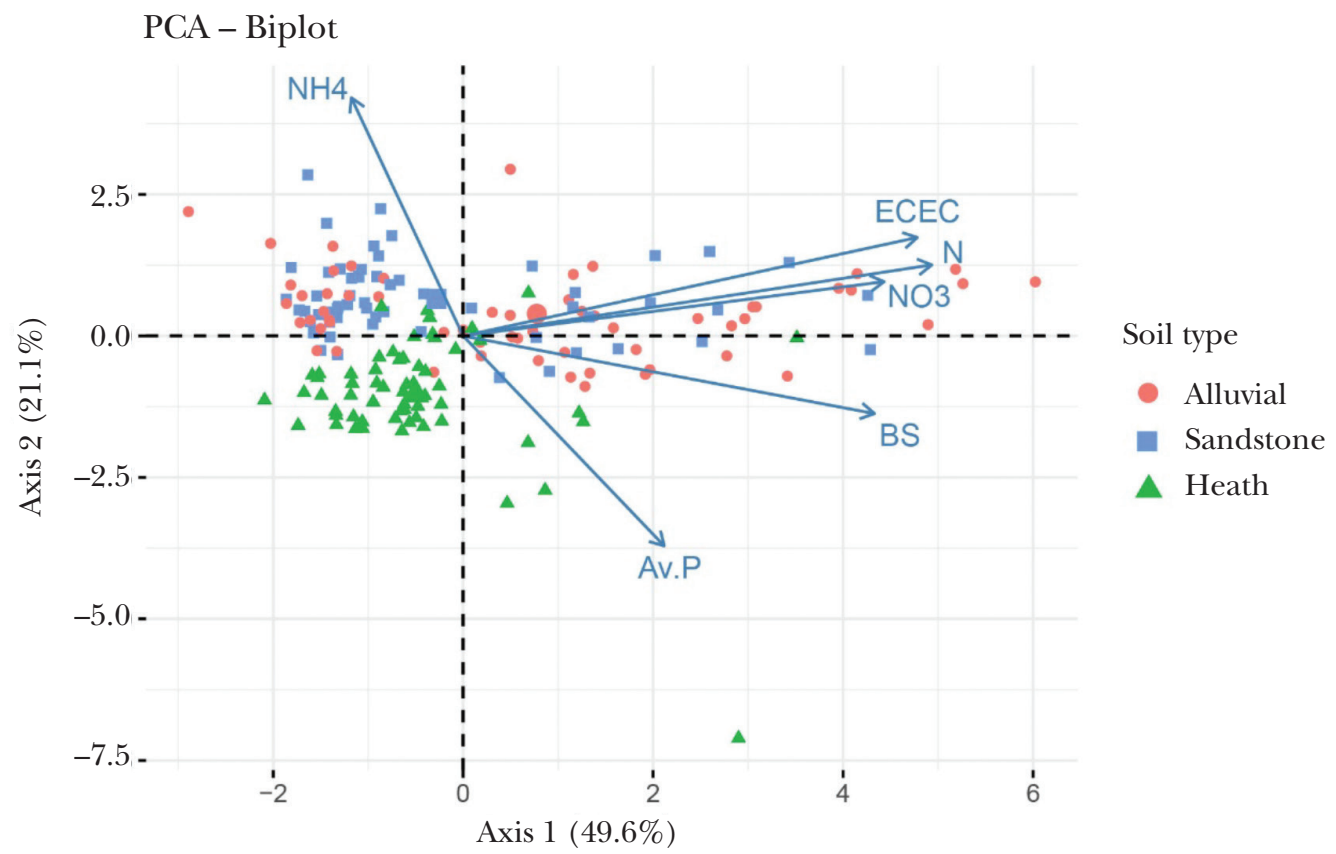

Figure 1A Principal component analysis biplot built with only effective cation exchange capacity (ECEC), base saturation (BS), available phosphorus (Av.P), ammonium (NH4), nitrate (NO3) and total $\mathrm{N}(\mathrm{N})$ to account for soil fertility among the three soil types studied at the Kabili-Sepilok Forest Reserve, Sabah, Malaysia 